\title{
Managing and Internet Service Bus
}

\author{
Donald F. Ferguson \\ Chief Architect, Enterprise IT Management Products \\ CA, Inc. \\ donald.ferguson@ca.com
}

\begin{abstract}
SOA and Web services have profoundly changed enterprise and commercial applications. BPEL, dynamic binding via service registries and repositories, alignment of grid computing with Web service standards, and a common approach to SOA and event driven architectures are examples of technologies that enable a new approach to applications and solutions. Many papers and talks have explained these technologies and their benefits. Systems and application management using Web services is a growing area that builds on these technologies. There are many benefits to a common SOA/Web service approach to modeling, developing, deploying, managing and optimizing SW solutions. This presentation explains the benefits.

Several significant intellectual challenges hinder realizing the promise of a SOA/Web service approach to systems and application management. One of the most important is "managing from a business service perspective." Business professionals have a completely different definition of "service" from technical professionals. Enterprises think in terms of IT realization of "business services," for example online banking or shipped package tracking. The business services are an interacting fabric of SOA services, and in many cases the enterprise does not fully understand which services interact in a business solution or to process a request. Many elements in the business service are not SOA services, for example databases, directories, file servers, etc.

This talk provides a deeper explanation of the business problem and challenges. The talk also explains the state of the art for solving some of the challenges. Finally, the talk concludes with suggestions for research and projects.
\end{abstract}

